\title{
Componentes de produção, produtividade e eficiência da irrigação do feijão-caupi no cerrado de Roraima
}

\author{
Viviana da E. R. Locatelli ${ }^{1}$, Roberto D. de Medeiros ${ }^{2}$, Oscar J. Smiderle ${ }^{3}$, \\ ${ }^{1}$ NATURATINS. Tocantinópolis, TO. E-mail: viviana_en@yahoo.com.br (Autor correspondente) \\ ${ }^{2}$ EMBRAPA. Boa Vista, RR. E-mail:roberto.medeiros@embrapa.br \\ ${ }^{3}$ EMBRAPA. Boa Vista, RR. E-mail:oscar.smiderle@embrapa.br \\ ${ }^{4}$ POSAGRO/UFRR. Boa Vista, RR. E-mail: anchietaufrr@gmail.com \\ ${ }^{5}$ POSAGRO/UFRR. Boa Vista, RR. E-mail: wellington.araujo@ufrr.br \\ ${ }^{6}$ DSEA/UFRR. Boa Vista, RR. E-mail: ktagianne@hotmail.com
} José de A. A. de Albuquerque ${ }^{4}$, Wellington F. Araújo ${ }^{5} \&$ Kelly T. S. de Souza ${ }^{6}$

\section{Palavras-chave:}

Vigna unguiculata

savana

cultivares

\begin{abstract}
R E S U M O
Neste trabalho objetivou-se avaliar os componentes de produção, produtividade e eficiência da irrigação do feijãocaupi em lâminas de irrigação no cerrado de Roraima. Conduziu-se o experimento no Campo experimental Água Boa, da Embrapa Roraima, em cultivo sobre palhada sob irrigação por aspersão convencional, de fevereiro a abril e de setembro a novembro de 2012. Foram testadas cinco lâminas de irrigação 30, 60, 90, 120 e 150\% da evapotranspiração de referência (ETo) e três cultivares de caupi: BRS Guariba, BRS Novaera e BRS Pajeú. Foram estabelecidas as lâminas com base em frações da ETo diária do tanque classe A. O delineamento foi em blocos casualizados com tratamentos dispostos em faixas e parcelas subdivididas, com cinco repetições. Avaliaram-se o número de vagens por planta, número de grãos por vagem, massa de cem grãos, produtividade de grãos secos e a eficiência do uso da água. Concluiu-se que as variáveis do BRS Pajeú não foram influenciadas pelos tratamentos, os cultivares BRS Guariba e BRS Novaera obtiveram a máxima produtividade de grãos, $1.275,19$ e $1.504,98 \mathrm{~kg} \mathrm{ha}^{-1}$, com as respectivas lâminas 74,3 e $94,02 \%$ da ETo. A máxima eficiência da irrigação foi obtida com a lâmina de $30 \%$ da ETo para os três cultivares.
\end{abstract}

Key words:

Vigna unguiculata

savana

cultivars

\section{Components of production, productivity and efficiency of irrigation of bean-cowpea in the 'Cerrado' of Roraima}

\begin{abstract}
A B S T R A C T
The objective of this study was to evaluate the components of production, productivity and irrigation efficiency of cowpea under irrigation in the 'Cerrado' of Roraima. The experiment was conducted at Experimental Farm 'Agua Boa'-EMBRAPA Roraima in cultivation on straw under irrigation by sprinkler from February to April and from September to November 2012. Five irrigation levels (30, 60, 90, 120 and 150\% of the reference evapotranspiration ETo) and three cowpea cultivars: (Guariba BRS, Novaera BRS and Pajeú BRS) were tested. The depths of irrigation established were based on fractions of the daily ETo (Pan Class A). The experimental design was in randomized blocks with treatments arranged in bands, split-plot, and five replications. The variables evaluated were: number of pods per plant, number of seeds per pod, weight of hundred grains, dry grain yield and efficiency of water use. It was observed that the variables of BRS Pajeú were not affected by treatments. Novaera BRS and BRS Guariba had the highest grain yield, 1275.19 and $1504.98 \mathrm{~kg} \mathrm{ha}^{-1}$, respectively, with irrigation depths equivalent to 74.3 and 94.02\% of ETo. The maximum irrigation efficiency was obtained with $30 \%$ ETo for all three cultivars.
\end{abstract}

\section{INTRODUÇÃO}

No Brasil, principalmente nas regiões Norte e Nordeste, o feijão-caupi se apresenta como cultivo secundário visando garantir alimento por determinado período; seu excedente é comercializado em feiras de produtores nas áreas urbanas mais próximas. No estado de Roraima, o feijão-caupi é cultivado em pequenas áreas quase sempre consorciado com outras culturas, como o milho e a mandioca (Alves et al., 2009). Ao ser cultivado em sistema consorciado a produtividade de grãos é reduzida independentemente dos sistemas, quando comparado ao monocultivo (Alves et al., 2009; Albuquerque et al., 2012).

Esta realidade vem mudando ao longo dos anos com a inserção de tecnologias inovadoras e conservacionistas, como a utilização de cultivares altamente produtivas com resistência às doenças e tolerantes à seca e o cultivo sobre palhada morta, mais conhecido como plantio direto e aliados à irrigação pode-se, obter resultados economicamente satisfatórios para agricultores 
familiares e empresariais, garantindo emprego, renda e alimento a população.

No período de 2001 a 2009, 23 cultivares de feijão-caupi foram lançadas para as regiões Norte, Nordeste e Centro-Oeste do Brasil apresentando alto potencial produtivo, portes variando de semiprostrado a semiereto, ciclo de maturidade fisiológica de médio a precoce, tipos comerciais diferentes e resistentes a pragas e doenças (Vilarinho et al., 2009).

Em Roraima se destacam, dentre as recomendadas para cultivo no estado, as BRS Guariba e BRS Novaera de portes semiereto, e BRS Pajeú de porte semiprostrado (Vilarinho et al., 2009).

A resposta dos cultivares à irrigação em geral é elevada cuja produção é direcionada a grãos verdes e grãos secos (Alves et al., 2009).

Um aspecto inovador em relação ao manejo de irrigação em feijão-caupi é a introdução de cobertura morta sobre o solo haja vista que a presença de palhada na superfície do solo em quantidade adequada é de grande importância na agricultura irrigada. Ela altera a relação solo-água reduzindo a taxa de evapotranspiração das culturas, principalmente nos estádios em que o seu dossel não cobre totalmente o solo, o que resulta em redução na frequência de irrigação e economia nos custos de operação do sistema (Stone et al., 2006).

Para um manejo correto de irrigação deve-se levar em consideração a lâmina de água adequada para bom suprimento hídrico, evitando estresse à cultura o qual possa afetar o crescimento das plantas e os componentes de produção (Bezerra et al., 2003).

No entanto, os resultados não devem ser extrapolados para outras regiões devido a diferenças entre cultivares estudados e as condições edafoclimáticas entre os locais de condução de cada experimento (Ramos et al., 2012).

Em Roraima, Oliveira et al. (2011) avaliando o efeito da irrigação e doses de fósforo sobre o feijão-caupi cultivado em campo e em casa de vegetação, observaram que a menor lâmina de irrigação aplicada, $187 \mathrm{~mm}$, reduziu em 43,3\% a produção de grãos. Entretanto, pesquisas em manejo do sistema solo-água-planta em feijão-caupi não atendem às expectativas do avanço alcançado com o melhoramento genético havendo carência de informações sobre estratégias ótimas de irrigação que demonstrem a influência sobre as características vegetativas e de produção dos cultivares recomendados para a região Norte.

O objetivo deste estudo foi avaliar o desempenho de feijãocaupi sob cinco lâminas de irrigação, cultivado sobre palhada no cerrado roraimense.

\section{Material e Métodos}

Dois experimentos foram realizados nos períodos de fevereiro a abril e de setembro a novembro de 2012, no Campo Experimental Água Boa - CEAB, pertencente à Embrapa Roraima, no município de Boa Vista (2॰49' $11^{\prime \prime} \mathrm{N}, 60^{\circ} 40^{\prime}$ 24 " W) e $85 \mathrm{~m}$ de altitude. Para as características avaliadas foram usadas as médias dos tratamentos, obtidas de ambos os experimentos.

O clima da região, segundo a classificação de Köppen, é do tipo Aw, tropical chuvoso, com precipitação média anual de aproximadamente $1.700 \mathrm{~mm}$ e umidade relativa do ar em torno de $70 \%$.

O solo da área de estudo é classificado como Latossolo Amarelo cuja análise dos atributos químicos e físicos é apresentada na Tabela 1, a qual foi realizada no laboratório de análise de solo, Embrapa Roraima - Manual de Métodos de Análise do Solo da EMBRAPA (1997).

Nos dois cultivos a semeadura do feijão foi realizada no sistema de plantio direto sobre a palhada de Brachiaria ruziziensis, 15 dias após a dessecação das plantas de cobertura, feita com Glyfosate. As sementes foram inoculadas no dia do plantio com Bradyrhizobium elkanii, na proporção de $100 \mathrm{~g}$ de inoculante misturado com $30 \mathrm{~mL}$ de água para $50 \mathrm{~kg}$ de sementes. A adubação de plantio foi realizada com $70 \mathrm{~kg} \mathrm{ha}^{-1}$ de superfosfato simples para os dois cultivos, já a de cobertura foi realizada com $40 \mathrm{~kg} \mathrm{ha}^{-1}$ de cloreto de potássio aplicados 8 dias após a emergência das plantas.

Para a semeadura foram feitas a abertura dos sulcos com cultivador e a distribuição das sementes, manualmente, em linhas espaçadas $0,5 \mathrm{~m}$ com a densidade de oito sementes por metro linear, para os cultivares BRS Guariba e BRS Novaera e cinco sementes para a BRS Pajeú.

O herbicida Glyphosate (glifosato) pós-emergente foi aplicado utilizando-se pulverizador costal pressurizado com $\mathrm{CO}_{2}$, pressão constante de 25 libras pol$^{-2}$, equipado com barra

Tabela 1. Atributos químicos e físicos do solo nas camadas $0-20 \mathrm{~cm}$ e $20-40 \mathrm{~cm}$ da área de estudo sobre palhada de Brachiaria ruziziensis, na savana de Roraima. Boa Vista, RR. 2012

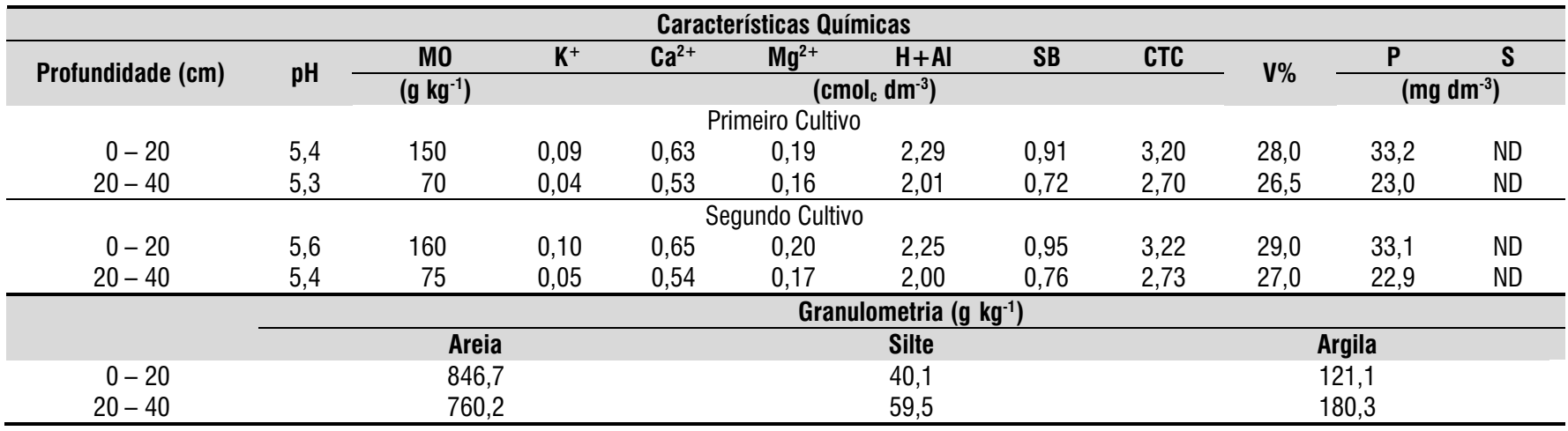


de pulverização de $2 \mathrm{~m}$ e volume de calda de $250 \mathrm{~L} \mathrm{ha}^{-1} \mathrm{e}$ para o controle de pragas foi utilizado o inseticida sistêmico Tiametoxam $250 \mathrm{~g} \mathrm{~kg}^{-1}$.

Utilizou-se o sistema de irrigação por aspersão convencional fixo-portátil disposto em faixas, composto por uma linha principal fixa, com ramais contendo sete aspersores espaçados $6,0 \times 24 \mathrm{~m}$; os aspersores utilizados apresentavam as seguintes características: marca Asperjato, diâmetro dos bocais de 3,2 x $2,0 \mathrm{~m}$, pressão de serviço de 28 m.c.a. e vazão de $980 \mathrm{~L} \mathrm{~h}^{-1} \mathrm{com}$ intensidade de aplicação de 13,6 $\mathrm{mm} \mathrm{h}^{-1}$.

As irrigações ocorreram diariamente repondo-se a lâmina de irrigação correspondente ao percentual de cada tratamento, de acordo com a evaporação do tanque classe A, segundo Bernardo (1986) por meio da Eq. 1:

$$
\mathrm{ETo}=\mathrm{Kt} . \mathrm{Ev}
$$

em que:

ETo - evapotranspiração potencial de referência

Kt - coeficiente do tanque adotado 0,75 , conforme média de dados climáticos observados para a área no período de dois anos

Ev - evaporação do tanque, $\mathrm{mm} \mathrm{d}^{-1}$

Três cultivares de feijão-caupi foram testadas: BRS Guariba e BRS Novaera de porte semiereto, maturação uniforme e ciclo entre 60-65 dias e a BRS Pajeú de porte semiprostrado, maturação desuniforme e ciclo entre 65-70 dias, todas de hábito de crescimento indeterminado combinadas com cinco lâminas de água correspondentes a 30, 60, 90, 120 e 150\% de ETo definidas com base em frações de ETo diárias, estimadas por meio do tanque classe $\mathrm{A}$ instalado próximo à área experimental adotando-se Kt de 0,75 ao longo do experimento. Para maior precisão dos dados foram verificados os dados meteorológicos obtidos da estação agrometeorológica automática, instalada próximo ao experimento.

O delineamento experimental foi em blocos ao acaso com parcelas subdivididas com cinco repetições em que as parcelas de $282,75 \mathrm{~m}^{2}(6,5 \times 43,5 \mathrm{~m})$ foram constituídas pelas lâminas de irrigação e as subparcelas de $12,5 \mathrm{~m}^{2}(2,5 \times 5,0 \mathrm{~m})$ pelos cultivares. Cada subparcela foi formada por cinco fileiras de 5,0 $\mathrm{m}$ de comprimento, sendo que, a área útil foi formada por três fileiras eliminando-se $0,5 \mathrm{~m}$ em cada extremidade.

As lâminas aplicadas foram medidas através de pluviômetros alternativos confeccionados com material plástico reciclado e instalados nas faixas irrigadas e só então distribuídos de maneira uniforme, durante todo o ciclo, a lâmina foi definida pela média da água coletada nesses pluviômetros os quais foram instalados na altura das plantas.

Esses dados serviram para estimar a lâmina aplicada em cada tratamento e calcular o coeficiente de uniformidade de distribuição de água realizado no período de instalação dos experimentos utilizando-se o coeficiente de Christiansen (1942) de acordo com a Eq. 2:

$$
\mathrm{CUC}=1-\left(\sum_{\mathrm{i}}^{\mathrm{n}}=1\left[\underline{\left.\mathrm{x}_{1}-\overline{\mathrm{x}}\right]}\right) / \mathrm{n} \cdot \overline{\mathrm{x}}\right.
$$

em que:

CUC - coeficiente de uniformidade de Christiansen, decimal

n - número de observações

$\mathrm{X}_{\mathrm{i}}$ - lâmina de irrigação aplicada no i-ésimo ponto da superfície do solo

x - lâmina média aplicada

O coeficiente de Christiansen resultou em $81 \%$ para uma média de velocidade de vento de $1,7 \mathrm{~m} \mathrm{~s}^{-1}$.

As irrigações ocorreram no período das 17 às $19 \mathrm{~h}$ e entre 6 e 8 h da manhã quando, praticamente, ainda não havia vento naquele local, o que propiciou maior uniformidade de distribuição da água.

A colheita de grãos foi realizada aos 63 dias após a emergência (DAE). Obteve-se o número de vagens por planta (NVP) pela média da coleta das vagens de cinco plantas representativas no período da colheita. O número de grãos por vagem (NGV) foi quantificado em 10 vagens coletadas ao acaso durante a colheita de grãos secos enquanto a massa de cem grãos (MCG) foi determinada conforme as Regras para Análise de Sementes (Brasil, 2009). Enfim, a produtividade de grãos secos (PGS) foi determinada a partir da média obtida nos dois cultivos para os cinco tratamentos por meio da colheita de grãos secos na área útil de cada subparcela, corrigindo a umidade para 13\% e expressa em $\mathrm{kg} \mathrm{ha}^{-1}$.

A eficiência do uso da água (EUA) para produtividade de grãos foi determinada por meio da relação entre a produção de grãos em $\mathrm{kg} \mathrm{ha}^{-1}$ e a lâmina total de água aplicada em $(\mathrm{mm})$ correspondente ao percentual da Evapotranspiração de referência (ETo), expressa, portanto, em $\mathrm{kg} \mathrm{mm}^{-1}$.

Os resultados foram submetidos à análise de variância com aplicação do teste $\mathrm{F}(\mathrm{p}<0,05)$. Realizou-se análise de regressão na presença de efeito significativo para lâminas e interações considerando-se as médias ajustadas com $\mathrm{R}^{2} \geq 50 \%$. Na presença de efeito significativo para cultivar e interações foi realizada comparação de médias pelo teste de Tukey $(\mathrm{p} \leq 0,05)$ através do software SISVAR, versão 5.3.

\section{Resultados e Discussão}

Os resultados da análise de variância das características número de vagem por planta, número de grãos por vagem e massa de cem grãos, são apresentados na Tabela 2. Apenas a massa de cem grãos apresentou influência estatística pela interação lâminas de irrigação versus cultivar; o fator lâmina influenciou o número de vagens por planta; já o fator cultivar afetou significativamente tanto o número de vagens por planta quanto o número de grãos por vagem (Tabela 2 ).

Quanto aos efeitos dos cultivares sobre o NVP (Tabela 2) verifica-se diferença significativa entre as médias proporcionadas pelos cultivares. A BRS Novaera apresentou maior número de vagens por planta $(12,84)$ seguida da BRS Pajeú cuja média $(11,08)$ foi superior à média $(9,5)$ obtida pelo cultivar BRS Guariba. Esta diferença no número de vagens por planta entre cultivares pode estar relacionada às características de cada cultivar. 
Tabela 2. Resumo das análises de variância para número de vagem por planta (NVP), número de grãos por vagem (NGV) e massa de cem grãos (MCG)

\begin{tabular}{lrccc}
\hline \multirow{2}{*}{ FV } & GL & \multicolumn{3}{c}{ Quadrado médio } \\
\cline { 3 - 5 } Bloco & 4 & NVP & NGV & MCG (g) \\
Lâmina & 4 & $15,73 *$ & 3,70 & 0,12 \\
Erro a & 16 & $1,56^{\text {ns }}$ & $2,52^{\star *}$ \\
Cultivar & 2 & $70,02^{\star *}$ & $226,88^{\star *}$ & $93,59^{\star *}$ \\
Lam*Cult & 8 & $5,34^{\text {ns }}$ & $1,24^{\text {ns }}$ & $0,52^{*}$ \\
Erro b & 40 & & & \\
CV 1 (\%) & & 19,66 & 9,58 & 1,85 \\
CV 2 (\%) & & 17,81 & 11,42 & 2,43 \\
\hline Cultivar & & & Médias \\
BRS Guariba & & $9,498 \mathrm{c}$ & $12,254 \mathrm{~b}$ & $19,632 \mathrm{~b}$ \\
BRS Novaera & & $12,844 \mathrm{a}$ & $7,962 \mathrm{c}$ & $22,356 \mathrm{a}$ \\
BRS Pajeú & & $11,084 \mathrm{~b}$ & $13,770 \mathrm{a}$ & $18,613 \mathrm{c}$ \\
Média geral & & 11,14 & 11,33 & 20,2 \\
\hline
\end{tabular}

ns Não significativo; * Significativo a 0,05 de probabilidade; ** Significativo a 0,01 de probabilidade, pelo teste F. Médias seguidas da mesma letra, na coluna, não diferem entre si pelo teste de Tukey $(p<0,05)$

Quanto às médias do NVP obtidas em função das lâminas de irrigação (Figura 1A), verifica-se que o NVP aumentou com o incremento das lâminas de irrigação atingindo o ponto de máxima eficiência técnica ( 12 vagens por planta) com a lâmina de $108,6 \%$, equivalente a $247,4 \mathrm{~mm}$.

Tais resultados corroboram com observações feitas por Nascimento et al. (2004) que, avaliando o efeito da variação de níveis de água disponível no solo sobre o crescimento e a produção de feijão-caupi, vagens e grãos verdes, verificaram que o número de vagens por planta foi influenciado pelas lâminas de água sendo mais afetado pelo déficit hídrico. Andrade Júnior et al. (2002), analisando níveis de irrigação para o caupi no Piauí, verificaram que o componente de produção com maior variabilidade positiva em resposta ao aumento da produtividade de grãos foi o número de vagens por planta.

Infere-se que a resposta observada para o número de vagens por planta em função das lâminas irrigação pode estar relacionada aos cultivares, uma vez que, geralmente, os cultivares respondem satisfatoriamente à irrigação e às condições de cultivo favoráveis demonstrando todo o seu potencial produtivo.

O maior número médio de grãos por vagem $(13,8)$ foi obtido com o cultivar BRS Pajeú seguido do obtido com o cultivar BRS Guariba (12,3 grãos por vagem) que, por sua vez, superou em $54 \%$ a obtida (7,96 grãos por vagem) pelo cultivar BRS Novaera (Tabela 2).

Os cultivares BRS Novaera e BRS Pajeú apresentaram médias de grãos por vagem inferiores às observadas por Vilarinho et al. (2009) que foram 10 e 16, respectivamente; entretanto, para o cultivar BRS Novaera o resultado corrobora com os encontrados por Oliveira et al. (2011) os quais obtiveram, trabalhando com o mesmo cultivar e quatro diferentes lâminas de água em Roraima, médias entre 7,0 e 7,53 grãos por vagem; para a BRS Guariba a média observada está de acordo com os valores apresentados por esta cultivar em ensaio de valor de cultivo e uso, realizado por Vilarinho et al. (2009).

Para Oliveira et al. (2003) o componente número de grãos por vagem é de pouca importância direta na seleção para o aumento da produtividade; de conformidade com Lopes et al. (2011), esta variável é uma característica de alta herdabilidade genética sendo pouco influenciada pelo ambiente.

Para o cultivar BRS Pajeú a massa de cem grãos não foi influenciada pelas lâminas de irrigação obtendo-se, assim, média de 18,61 g. Segundo Ferreira et al. (1991) este componente de produção resiste normalmente às modificações induzidas por estresse ambiental.
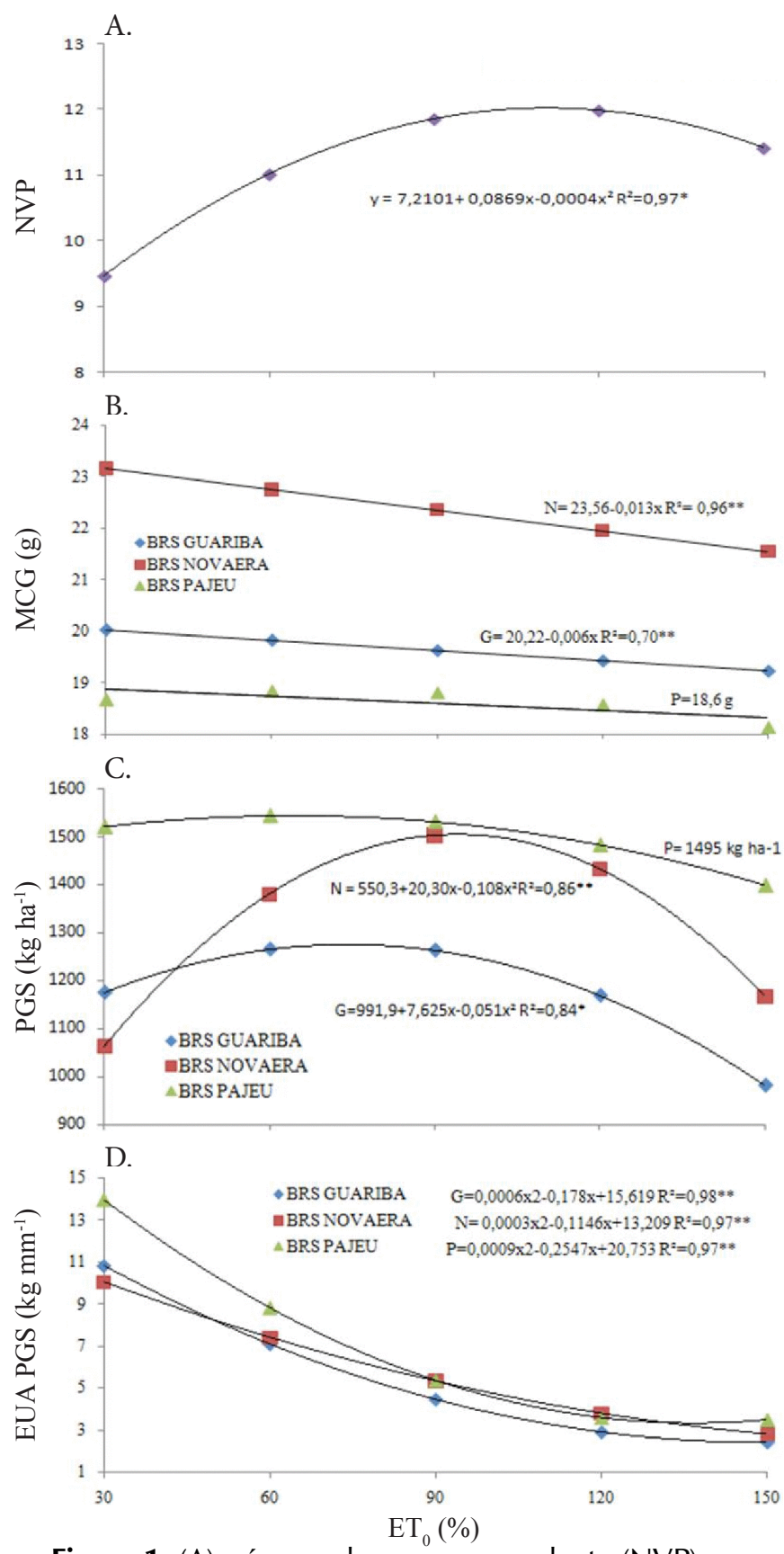

Figura 1. (A) número de vagens por planta (NVP) em função de lâminas de irrigação; (B) massa de cem grãos (MCG) em função de lâminas de irrigação e cultivares de feijão-caupi; (C) produtividade de grãos (PGS) em função de lâminas de irrigação para os três cultivares de feijãocaupi e (D) eficiência do uso da água para produtividade de grãos (EUA) em função de lâminas de irrigação e cultivares de feijão-caupi no cerrado de Roraima, 2012 
O cultivar BRS Novaera mostrou-se superior aos demais com valores de MCG superiores a $22 \mathrm{~g}$ sendo que a BRS Guariba e BRS Pajeú apresentaram médias de 19,63 e 18,61 g, respectivamente. Ressalta-se, porém, que os cultivares BRS Guariba e BRS Novaera superaram as médias obtidas por Vilarinho et al. (2009) de 19,5 g para BRS Guariba e 20 g para BRS Novaera enquanto para a BRS Pajeú esses autores obtiveram, em ensaios, a média de $21 \mathrm{~g}$ superando, portanto, a obtida nesses experimentos; mesmo assim, concordam com Bezerra et al. (2003), Mendes et al. (2007) e Ramos et al. (2012) ao constatarem que a massa de cem grãos não foi afetada pela deficiência hídrica.

Para os efeitos observados com os cultivares BRS Guariba e BRS Pajeú verifica-se semelhança com a observação feita por Shouse et al. (1981) os quais afirmam haver uma relação fonte dreno refletida por este componente de produção quando, no momento em que a massa de cem grãos é reduzida, indica que está ocorrendo limitação da produção na fonte. Este fato pode ocorrer em virtude do aumento no número de vagens, como no caso de tratamentos adequadamente irrigados ou pelo efeito do estresse hídrico sobre a fotossíntese ou, ainda, translocação de fotoassimilados em que, neste caso e segundo Costa et al. (1997), o número de vagens por planta é inversamente proporcional à massa de cem grãos refletindo em uma compensação para limitações de tamanho do dreno, apesar do cultivar BRS Novaera se tenha mostrado totalmente contrário a esta observação apresentando o maior número de vagens por planta e, em contrapartida, maior massa de cem grãos.

A produtividade de grãos e a eficiência de uso da água foram influenciadas pelas lâminas de irrigação, pelos cultivares e pela interação lâmina de irrigação versus cultivar, conforme a Tabela 3.

As produtividades de grãos secos obtidas em função dos efeitos dos cultivares dentro das lâminas de irrigação, estão apresentadas na Tabela 4 e as médias obtidas em função do desdobramento dos efeitos das lâminas dentro de cultivares, estão na Figura 1C.

Tabela 3. Resumo das análises de variância para produtividade de grãos secos (PGS) e eficiência do uso da água para produtividade de grãos secos (EUA PGS)

\begin{tabular}{|c|c|c|c|}
\hline \multirow{2}{*}{ FV } & \multirow{2}{*}{ GL } & \multicolumn{2}{|c|}{ Quadrado médio } \\
\hline & & PGS (kg ha-1) & Ef.UA PGS \\
\hline Bloco & 4 & 50859,7 & 1,16 \\
\hline Lâmina & 4 & $202903,7^{* *}$ & $197,03 * *$ \\
\hline Erro a & 16 & & \\
\hline Cultivar & 2 & $664379,93 * \star$ & $15,55^{\star \star}$ \\
\hline Lam*Cult & 8 & $52415,21^{*}$ & 3,60 ** \\
\hline Erro b & 40 & & \\
\hline CV $1(\%)$ & & 8,92 & 10,37 \\
\hline CV 2 (\%) & & 10,96 & 10,50 \\
\hline Cultivar & & \multicolumn{2}{|c|}{ Médias } \\
\hline BRS Guariba & & $1170,19 \mathrm{c}$ & $5,548 \mathrm{~b}$ \\
\hline BRS Novaera & & $1308,85 b$ & $5,882 \mathrm{~b}$ \\
\hline BRS Pajeú & & $1495,07 \mathrm{a}$ & $7,050 \mathrm{a}$ \\
\hline Média geral & & 1324,70 & 6,160 \\
\hline
\end{tabular}

ns, * ** Não significativo, significativo a 0,05 e 0,01 de probabilidade, respectivamente, pelo teste F. Médias seguidas pela mesma letra na coluna não diferem entre si pelo teste de Tukey a 0,05 de probabilidade
Tabela 4. Médias de produtividade de grãos secos obtidas em função do desdobramento da interação de cultivar versus lâminas de água, no cerrado de Roraima

\begin{tabular}{cccc}
\hline Lâminas & \multicolumn{3}{c}{ Produtividade de grãos secos (kg ha $^{-1}$ ) } \\
\cline { 2 - 4 } (\%ETo) & BRS Guariba & BRS Novaera & BRS Pajeú \\
30 & $1190,67 \mathrm{~B}$ & $1113,60 \mathrm{~B}$ & $1545,07 \mathrm{~A}$ \\
60 & $1247,99 \mathrm{~B}$ & $1268,67 \mathrm{~B}$ & $1496,00 \mathrm{~A}$ \\
90 & $1215,60 \mathrm{~B}$ & $1529,60 \mathrm{~A}$ & $1524,13 \mathrm{~A}$ \\
120 & $1247,33 \mathrm{~B}$ & $1508,27 \mathrm{~A}$ & $1538,80 \mathrm{~A}$ \\
150 & $949,33 \mathrm{~B}$ & $1124,13 \mathrm{~B}$ & $1371,33 \mathrm{~A}$ \\
Média & $1170,19 \mathrm{C}$ & $1308,85 \mathrm{~B}$ & $1495,07 \mathrm{~A}$ \\
\hline
\end{tabular}

Médias seguidas pela mesma letra, na linha, não diferem entre si pelo teste de Tukey a 0,05 de probabilidade

Verifica-se, na Tabela 4, que a produtividade de grãos foi influenciada pelo fator cultivar sendo que a BRS Pajeú proporcionou maior produtividade de grãos em relação às médias obtidas com a BRS Guariba, sob todas as lâminas de irrigação e em relação às médias obtidas com a BRS Novaera sob as lâminas de 30, 60 e 150\% da Eto; apenas nas lâminas de irrigação de 90 e $120 \%$ da ETo, correspondentes a 273,7 e $356,9 \mathrm{~mm}$, respectivamente, a BRS Novaera apresentou produtividade de grãos estatisticamente igual à obtida com a BRS Pajeú, ambos superiores à da BRS Guariba.

A média de produtividade obtida para o cultivar BRS Novaera $\left(1308,85 \mathrm{~kg} \mathrm{ha}^{-1}\right)$ foi superior à constatada por Vilarinho et al. (2009) em ensaio de valor de cultivo e uso, de $1242,9 \mathrm{~kg} \mathrm{ha}^{-1}$ já a BRS Guariba apresentou produtividade média de 1107,19 $\mathrm{kg} \mathrm{ha}^{-1}$, sendo inferior à obtida por Vilarinho et al. (2009), 1783 $\mathrm{kg} \mathrm{ha}^{-1}$. A BRS Pajeú se destacou entre as demais, apresentando a maior produtividade de grãos $1545,07 \mathrm{~kg} \mathrm{ha}^{-1}$ obtida com a aplicação da lâmina de $30 \%$ da ETo, correspondente a 107,3 mm.

Resultado análogo foi obtido por Andrade et al. (2002) que trabalhando com cultivares de caupi de portes semiereto e semiprostrado, obtiveram respostas diferenciadas entre os cultivares quanto às lâminas de irrigação aplicadas em que o cultivar de porte semiereto apresentou máxima produtividade de grãos com a lâmina correspondente a $449,0 \mathrm{~mm}$ e a de semiprostrado com a lâmina de $389,9 \mathrm{~mm}$.

Quanto ao desdobramento dos efeitos das lâminas de irrigação dentro de cultivares (Figura 1C) observa-se que a produtividade de grãos para as BRS Guariba e BRS Novaera se ajustou ao modelo de regressão polinomial quadrático sinalizando desempenho diferenciado entre os cultivares. Trabalhos com lâminas de água e feijão-caupi foram realizados sobretudo para a região Nordeste, em que Andrade Júnior et al. (2002), Nascimento et al. (2004), Andrade et al. (2008), Blanco et al. (2011), Souza et al. (2011), Bastos et al. (2012) e Ramos et al. (2012) obtiveram resultados satisfatórios em produtividade de grãos verdes e secos utilizando lâminas de água no intervalo de 300 a $430 \mathrm{~mm}$.

Os cultivares BRS Guariba e BRS Novaera atingiram a máxima eficiência técnica para as produtividades 1275,19 e $1504,98 \mathrm{~kg} \mathrm{ha}^{-1} \mathrm{com}$ as respectivas lâminas $157,27 \mathrm{~mm}$ $(74,3 \% \mathrm{ETo})$ e $199 \mathrm{~mm}(94,02 \% \mathrm{ETo})$ resultados que diferem dos observados por Blanco et al. (2011), Ramos et al. (2012) e Gomes et al. (2012) que obtiveram as maiores produtividade com a aplicação das maiores lâminas de irrigação podendo, 
ainda, contribuir para esses resultados a presença da palhada na superfície do solo. Por sua vez, resultados semelhantes foram obtidos por Souza et al. (2011) cuja aplicação da lâmina de 100\% da ETo resultou em maior produtividade de grãos totalizando $1374,7 \mathrm{~kg} \mathrm{ha}^{-1} \mathrm{e}$ a lâmina de $125 \%$ resultou em diminuição da produtividade.

A utilização da irrigação no cultivo de feijão-caupi deve ser realizada com manejo adequado, ou seja, os cultivares respondem à irrigação até certa lâmina que, neste caso foi, para a BRS Novaera, com a lâmina de $94 \%$ ETo (199 mm) e a BRS Guariba com 74\% ETo (157,27 mm) sendo, então, desperdício, a utilização de lâmina superior a essas.

Se se comparar as médias apresentadas pelo cultivar BRS Pajeú nos tratamentos com as diferentes lâminas (Tabela 4) observar-se-á que apenas com a lâmina correspondente a $30 \%$ da ETo este cultivar manteve seu potencial produtivo, discordando de Carvalho et al. (2000); Oliveira et al. (2011); Ramos et al. (2012) e Bastos et al. (2012) os quais relatam que o incremento da irrigação resulta em aumento da produtividade mas se observa que este resultado pode estar relacionado ao sistema de cultivo sobre palhada, utilizado naqueles experimentos. Segundo Albuquerque (2008) a cobertura de palhada reduz em até $50 \%$ a evaporação do solo; da mesma forma, Arf et al. (2004) observaram que o tratamento com a menor lâmina de irrigação propicia produtividade de grãos semelhantes aos dos tratamentos com maior lâmina e, consequentemente, diminuição no custo com irrigação.

As respostas diferenciadas dos cultivares BRS Guariba, BRS Novaera e BRS Pajeú às lâminas de irrigação para produtividade de grãos, tornam-se resultados importantes no momento da escolha do cultivar para atender o mercado ao qual será destinada a produção.

Para o mercado de grãos secos são utilizados cultivares de porte semiereto e maturação uniforme, desde que seja possível a realização da colheita totalmente mecanizada; a BRS Novaera se encaixa neste perfil sendo possível obter, com este cultivar, além dessas características, uma produtividade economicamente satisfatória (1504 $\mathrm{kg} \mathrm{ha}^{-1}$ ) e menor custo com água utilizando apenas $94 \%$ de reposição da ETo o que corresponde à lâmina de 199mm sendo possível, ainda, com seu ciclo de 60-65 dias, realizar até três safras no período de seca com o uso da irrigação, em Roraima podendo ser apreciada por consumidores exigentes quanto ao gosto, cor e facilidade de preparo.

Com a BRS Guariba é possível atender tanto ao mercado de grãos secos quanto de grãos verdes; para grãos verdes apresenta vagens de fácil debulha e grãos que agradam tanto em cor quanto em paladar os consumidores. Para grãos secos é possível realizar a colheita mecanizada mesmo sem a dessecação pois se obteve, neste experimento, maturação uniforme com ciclo de até 65 dias sem necessitar de dessecação, podendo realizar mais de dois cultivos no período de seca em Roraima; contudo, a produtividade está abaixo da obtida com a BRS Novaera tal como a lâmina requerida.

O cultivar BRS Pajeú, por ser de porte semiprostrado, não se adequa à colheita mecanizada; mesmo assim, é apreciada por consumidores que preferem grãos mulatos claros de fácil cocção e agradável ao paladar. Para o mercado de grãos verdes tem um destaque especial visto que é possível obter mais de uma colheita em apenas um cultivo. Seu potencial produtivo pode ser superado apenas com a disponibilidade de uma lâmina de água de 30\% de reposição da ETo que corresponde a 107,3 $\mathrm{mm}$. Neste trabalho foi realizada apenas uma colheita de grãos secos para este cultivar sem uso de dessecante, o que mostra que este cultivar mantém, com o uso da irrigação, seu potencial produtivo com um ciclo de até 65 dias, sendo possível realizar mais de duas safras no período de seca, em Roraima.

Quanto à eficiência do uso da água para a produtividade de grãos o efeito médio das lâminas ajustou-se a uma função polinomial quadrática para os três cultivares (Figura 1D). Constatou-se redução da eficiência do uso da água com o incremento das lâminas, independentemente do cultivar; desta forma, as maiores eficiências para BRS Guariba $(9,74 \mathrm{~kg}$ $\left.\mathrm{mm}^{-1}\right)$, BRS Novaera $\left(10,04 \mathrm{~kg} \mathrm{~mm}^{-1}\right)$ e BRS Pajeú $(13,94 \mathrm{~kg}$ $\mathrm{mm}^{-1}$ ), foram obtidas com a lâmina de $30 \%$ da ETo $(107,3 \mathrm{~mm})$ proporcionando produtividades de 1190,67 $\mathrm{kg} \mathrm{ha}^{-1} \mathrm{com}$ o BRS Guariba, 1113,60 kg ha-1 com o BRS Novaera e $1545,7 \mathrm{~kg} \mathrm{ha}^{-1}$ com o BRS Pajeú.

Os cultivares BRS Guariba e BRS Novaera atingiram as máximas produtividades, $1275,19 \mathrm{~kg} \mathrm{ha}^{-1} \mathrm{e} 1504,98 \mathrm{~kg} \mathrm{ha}^{-1}$, com lâminas de 74,3\% ETo $(157,27 \mathrm{~mm})$ e 94,02\% ETo $(199 \mathrm{~mm})$, respectivamente correspondendo a uma EUA de 8,11 e 7,56 $\mathrm{kg} \mathrm{mm}^{-1}$ para BRS Guariba e BRS Novaera, respectivamente. Esta resposta foi similar à observada por Andrade Júnior et al. (2002) e Souza et al. (2011) que, avaliando a eficiência do uso da água para o feijão-caupi, observaram resposta quadrática com máxima EUA de 66,1 e $31,3 \mathrm{~kg} \mathrm{~m}^{-3}$ com a aplicação das lâminas $306,3 \mathrm{~mm}$ e $75 \%$ da ETo, respectivamente.

Segundo Andrade Júnior et al. (2002) referido resultado é um indicativo de que a aplicação das lâminas visando à máxima produção de grãos no nível obtido com a lâmina mais eficiente, evita o desperdício de água.

A disponibilidade de água é fator relevante a ser considerado quando se pretendem ganhos na produtividade de grãos do feijão-caupi o que pode ser obtido com um manejo adequado que proporcione a maximização da eficiência do uso da água.

\section{Conclusões}

1. As lâminas de irrigação não interferem no número de grãos por vagem dos cultivares avaliados.

2. O cultivar BRS Pajeú apresenta produtividade de grãos superior à BRS Guariba, independentemente da lâmina de irrigação.

3. Os cultivares BRS Guariba e BRS Nova era atingem a produtividade máxima de grãos $\left(1275,19 \mathrm{~kg} \mathrm{ha}^{-1}\right) \mathrm{e}(1504,98 \mathrm{~kg}$ $\left.\mathrm{ha}^{-1}\right)$ com a aplicação das lâminas $157,27 \mathrm{~mm}(74,3 \%$ da ETo) e $199 \mathrm{~mm}$ (94,02\% da ETo) respectivamente.

4. A máxima eficiência do uso da água é atingida com a lâmina de irrigação de $30 \%$ da ETo correspondente a 107,3 $\mathrm{mm}$, para os três cultivares. 


\section{Literatura Citada}

Albuquerque, J. A. A.; Sediyama, T.; Alves, J. M. A. ; Silva, A. A.; Uchoa, S. C. P. Cultivo de mandioca e feijão em sistemas consorciados realizado em Coimbra, Minas Gerais, Brasil. Revista Ciência Agronômica, v.43, p.532-538, 2012.

Albuquerque, P. E. P. Estratégias de manejo de irrigação. In: Albuquerque, P. E. P.; Durães, F. O. M. Uso e manejo de irrigação. Brasília: Embrapa Informação Tecnológica, 2008. p.449-486.

Alves, J. M. A.; Araújo, de N. P.; Uchôa, S. C. P.; Albuquerque, J. A. A.; Silva, A, J. da; Rodrigues, G. S.; Silva, D. C. O. da. Avaliação agroeconômica da produção de cultivares de feijão-caupi em consórcio com cultivares de mandioca em Roraima. Revista Agro@mbiente, v.3, p.15-30, 2009.

Andrade, E. M.; Palácio, H. A. Q.; Souza, I. H.; Leão, R. A. O.; Guerreiro, M. J. Land use effects in groundwater composition of an alluvial aquifer (Trussu River, Brazil) by multivariate techniques. Environmental Research, v.106, p.170-177, 2008.

Andrade, R. da S.; Moreira, J. A. A.; Stone, L. F.; Carvalho, J. de A. Consumo relativo de água do feijoeiro no plantio direto em função da porcentagem de cobertura morta do solo. Revista Brasileira de Engenharia Agrícola e Ambiental, v.6, p.35-38, 2002.

Andrade Júnior, A. S.; Rodrigues, B. H. N.; Frizzone, J. A.; Cardoso, M. J.; Bastos, E. A.; Melo, F. B. Níveis de irrigação na cultura do feijão-caupi. Revista Brasileira de Engenharia Agrícola e Ambiental, v.6, p.17-20, 2002.

Arf, O; Rodrigues, R. A. F; Sá, M. E de; Buzetti, S.; Nascimento, V. do. Manejo do solo, água e nitrogênio no cultivo de feijão. Pesquisa Agropecuária Brasileira, v.39, p.131-138, 2004.

Bastos, E. A.; Ramos, H. M. M.; Andrade Júnior, A. S de; Nascimento, F. N do; Cardoso, M. J. Parâmetros fisiológicos e produtividade de grãos verdes do feijão-caupi sob déficit hídrico. Water Resources and Irrigation Management, v.1, p.31-37, 2012.

Bernardo, S. Manual de irrigação. 4.ed. Viçosa: UFV, 1986. 488p.

Bezerra, F. M. L.; Araripe, M. A. E.; Teófilo E. M.; Cordeiro, L. G; Santos, J.J.A. dos. Feijão-caupi e déficit hídrico em suas fases fenológicas. Revista Ciência Agronômica, v.34, p.13-18, 2003.

Blanco, F. F.; Cardoso, M. J.; Freire Filho, F. R.; Veloso, M. E. da C.; Nogueira, C. C. P.; Dias, N. da S. Milho verde e feijão-caupi cultivados em consórcio sob diferentes lâminas de irrigação e doses de fósforo. Pesquisa Agropecuária Brasileira, v.46, p.524-530, 2011.

Brasil. Ministério da Agricultura, Pecuária e Abastecimento. Regras para análise de sementes. Ministério da Agricultura, Pecuária e Abastecimento. Secretaria de Defesa Agropecuária. Brasília: Mapa/ACS, 2009. 395p.

Carvalho, J. de A.; Pereira, G. M.; Andrade, M. J. B de; Roque, M. W. Efeito do déficit hídrico sobre o rendimento do feijão-caupi (Vigna unguiculata (L.) Walp.). Ciência e Agrotecnologia, v.24, p.710-717, 2000.

Costa, M. M. M. N.; Távora, F. J. A. F.; Pinho, J. L. N. de; Melo, F. I. O. Produção, componentes de produção, crescimento e distribuição das raízes de caupi submetido a deficiência hídrica. Pesquisa Agropecuária Brasileira, v.32, p.43-50, 1997.
Christiansen, E. J. Irrigation by sprinkler. In: Brouwer, C.; Prins, K.; Kay, M.; Heibloem, M. (ed.) Irrigation water management: Irrigation methods. Berkeley: Berkeley University of California, 1942. p.5-203.

EMBRAPA - Empresa Brasileira de Pesquisa Agropecuária. Centro Nacional de Pesquisa de Solos. Manual de métodos de análise de solo. 2.ed. Rio de Janeiro: EMBRAPA, 1997. $212 \mathrm{p}$.

Ferreira, L. G. R.; Costa, J. O.; Albuquerque, I. M. de. Estresse hídrico nas fases vegetativas e reprodutivas de duas cultivares de caupi. Pesquisa Agropecuária Brasileira, v.26, p.1049-1055, 1991.

Gomes, E. P.; Biscaro, G. A.; Ávila, M. R.; Loosli, F. S.; Vieira, C. V.; Barbosa, A. P. Desempenho agronômico do feijoeiro comum de terceira safra sob irrigação na região noroeste do Paraná. Semina: Ciências Agrárias, v.33, p.889-910, 2012.

Lopes, A. da S.; Oliveira, G. Q. de; Souto Filho, S. N.; Goes, R. J.; Camacho, M. A. Manejo de irrigação e nitrogênio no feijoeiro comum cultivado em sistema de plantio direto. Revista Ciência Agronômica, v.42, p.51-56, 2011.

Mendes, R. M. S.; Távora, F. J. A. F.; Pitombeira, J. B.; Nogueira, R. J. M. C. Relações fonte-dreno em feijão-de-corda submetido à deficiência hídrica. Revista Ciência Agronômica, v.38, p.95-103, 2007.

Nascimento, J. T.; Pedrosa, M. B.; Tavares Sobrinho, J. Efeito da variação de níveis de água disponível no solo sobre o crescimento e produção de feijão caupi, vagens e grãos verdes. Horticultura Brasileira, v.22, p.174-177, 2004.

Oliveira, F. J. de; Anunciação Filho, C. J. da; Bastos, G. Q.; Reis, O. V. dos; Teófilo, E. M. Caracteres agronômicos aplicados na seleção de cultivares de caupi. Revista Ciência Agronômica, v.34, p.5-11, 2003.

Oliveira, G. A.; Araújo, F. W; Cruz, P. L. S; Silva, W. L. M.; Ferreira, G. B. Resposta do feijão-caupi as lâminas de irrigação e as doses de fósforo no cerrado de Roraima. Revista Ciência Agronômica, v.42, p.872-882, 2011.

Ramos, H. M. M.; Bastos, E. A.; Andrade Júnior, A. S. de; Marouelli, W. A. Estratégias ótimas de irrigação do feijãocaupi para produção de grãos verdes. Pesquisa Agropecuária Brasileira, v.47, p.576-583, 2012.

Shouse, P.; Dasberg, S.; Jury, W. A.; Stolzy, L.M. Water déficits effects on water potential yield, and water use of cowpeas. Agronomy Journal, v.73. p.333-336, 1981.

Souza, L. S. B de; Moura, M. S. B. de; Sediyama, G. C.; Silva, T. G. F. da. Eficiência do uso da água das culturas do milho e do feijão-caupi sob sistemas de plantio exclusivo e consorciado no semiárido brasileiro. Bragantia, v.70, p.715-721, 2011.

Stone, L. F.; Silveira, P. M. da; Moreira, J. A. A; Braz, A. J. B. P. Evapotranspiração do feijoeiro irrigado em plantio direto sobre diferentes palhadas de culturas de cobertura. Pesquisa Agropecuária Brasileira, v.41, p.577-582, 2006.

Vilarinho, A.A.; Lopes, A.M; Freire Filho, F. R; Gonçalves, J. R. P; Alves, J. M. A.; Marinho, J. T. de S.; Vieira Júnior, J. R.; Cavalcante, E. da S. Melhoramento. In: Zilli, J. E.; Vilarinho, A. A.; Alves, J. M. A. A cultura do feijão-caupi na Amazônia Brasileira. Boa Vista: Embrapa Roraima, 2009. p.105-130. 